(c) The Authors 2019. This is an Open Access article, distributed under the terms of the Creative Commons Attribution licence (http:// creativecommons.org/licenses/by/4.0/), which permits unrestricted re-use, distribution, and reproduction in any medium, provided the original work is properly cited.

\title{
Inulin from Jerusalem artichoke tubers alleviates hyperglycaemia in high-fat- diet-induced diabetes mice through the intestinal microflora improvement
}

\author{
Tianyun Shao, Qiuhong Yu, Tingshuo Zhu, Anhong Liu, Xiumei Gao, Xiaohua Long* and Zhaopu Liu \\ College of Resources and Environmental Sciences, Nanjing Agricultural University, Nanjing, Jiangsu 210095, People's Republic \\ of China \\ (Submitted 12 February 2019 - Final revision received 2 September 2019 - Accepted 4 September 2019)
}

\section{Abstract}

The rate of hyperglycaemia in people around the world is increasing at an alarming rate at present, and innovative methods of alleviating hyperglycaemia are needed. The effects of Jerusalem artichoke inulin on hyperglycaemia, liver-related genes and the intestinal microbiota in mice fed a high-fat diet (HFD) and treated with streptozotocin (STZ) to induce hyperglycaemia were investigated. Inulin-treated hyperglycaemic mice had decreased average daily food consumption, body weight, average daily water consumption and relative liver weight and blood concentrations of TAG, total cholesterol, HDL-cholesterol and fasting blood glucose. Liver-related gene expressions in hyperglycaemic (HFD-fed and STZ-treated) compared with control mice showed eighty-four differentially expressed genes (forty-nine up-regulated and thirty-five down-regulated). In contrast, hyperglycaemic mice treated with inulin had twenty-two differentially expressed genes compared with control ones. Using Illumina high-throughput sequencing technology, the rarefaction and the rank abundance curves as well as the $\alpha$ diversity indices showed the treatment-induced differences in bacterial diversity in intestine. The linear discriminant analysis of effect size showed that the inulin treatment improved intestinal microbiota; in particular, it significantly increased the number of Bacteroides in the intestine of mice. In conclusion, inulin is potentially an effective functional food for the prevention and/or treatment of hyperglycaemia.

Key words: Jerusalem artichokes: Inulin: Hyperglycaemia: Enteric micro-organisms: Lipid genes

Nowadays, diabetes is a major health problem in developed as well as in developing countries. The proportion of diabetes in the population has increased year by year, becoming the third most serious disease after CVD and cancer. Diabetes is accompanied by cardiovascular complications. It is very difficult to predict the development of disease ${ }^{(1)}$. The prediction is that the world's population of type 2 diabetes will reach 366 million in $2030^{(2)}$. A complete or relative lack of insulin secretion and/or action can lead to diabetes and its complications ${ }^{(3)}$. There is a close association between diabetes and hyperlipidaemia and hypercholesterolaemia ${ }^{(4-4)}$. In addition, recent evidence suggests that changes in haematological parameters may lead to abnormal glucose metabolism and diabetes mellitus through increasing insulin resistance and liver dysfunction $^{(7,8)}$.

Intestinal microbiota plays an important role in the development of inflammation and metabolic disorders of obesity, insulin resistance and type 2 diabetes $^{(9)}$. The intestinal microbiota is considered to be a prescribed indicator for the management of type 2 diabetes and the prevention of other microscopic and macroscopic vascular diseases ${ }^{(10)}$. The intestinal microbiota may be related to the production of lipopolysaccharides and metabolic endotoxaemia ${ }^{(11)}$. Probiotics can restore intestinal microbiota of Akkermansia muciniphila in diabetics and obese subjects. Inulin can produce changes in intestinal bifidobacteria ${ }^{(12-14)}$ and Bacteroides as well as reduce the abundance of Firmicutes ${ }^{(15-17)}$.

Jerusalem artichoke (Heliantbus tuberosus L.) is a perennial tuber plant. Its tubers are made largely of carbohydrates, mainly in the form of inulin. Inulin is soluble fibre and contains a short chain of fructose molecules as $\beta-2,1$ fructan. Streptozotocin (STZ) is a toxic nitrosourea analogue, and it can selectively destroy specific pancreatic $\beta$ cells via GLUT2 in mice and rats ${ }^{(18,19)}$. STZ can inhibit the function of pancreatic $\beta$ cells and reduce the secretion of insulin. Hence, it is often used to establish the animal model of diabetes. Low-dose STZ can slightly damage the function of pancreatic $\beta$ cells and can moderately reduce insulin secretion,

Abbreviations: CP, positive control; FBG, fasting blood glucose; HFD, high-fat diet; LEfSe, linear discriminant analysis effect size; OTU, operational taxonomic units; RDP, Ribosome Database Project; STZ, streptozocin. 
creating symptoms similar to those in patients with type 2 diabetes insulin hyposecretion ${ }^{(20)}$.

In the present study, a repeatable experimental model of hyperlipidaemia-diabetic mice was induced by feeding a high-fat diet (HFD) for 1 consecutive month and multiple low doses $(50 \mathrm{mg} / \mathrm{kg}$ ) of STZ for 1 week. Considering Jerusalem artichoke inulin's potential health benefits, the present trial aimed to investigate its effects on fasting blood glucose (FBG) homoeostasis, average daily food consumption, body weight, average daily water consumption, relative liver weight, serum lipids level, liver-related gene expressions and intestinal microbiota in hyperlipidaemia-diabetes mice.

\section{Material and methods}

\section{Experimental material and chemicals}

Inulin (extracted from Jerusalem artichoke tubers) was purchased from the Qinghai Weide Biotechnology Co., Ltd.

The total sugar content was determined using the phenolsulphuric acid method. The purity of inulin was determined by subtracting the reducing sugar content from the total sugar content (3-amino-5-nitrosalicylic acid method) ${ }^{(21,22)}$. The purity of inulin was $90 \cdot 1 \%$.

Metformin $\mathrm{HCl}$ (1,1-dimethyl metformin $\mathrm{HCl}, \mathrm{C}_{14} \mathrm{H}_{11} \mathrm{~N}_{5} \cdot \mathrm{HCl}$, molecular weight $165.63 \mathrm{~g} / \mathrm{mol}$ ) tablets were purchased from Sino-American Shanghai Squibb Pharmaceuticals Ltd. Metformin $\mathrm{HCl}$ is a biguanide antihyperglycaemic drug administered orally alone or in combination with other hypoglycaemics in treating type 2 diabetes mellitus ${ }^{(23-26)}$. STZ $\left(\mathrm{C}_{8} \mathrm{H}_{15} \mathrm{~N}_{3} \mathrm{O}_{7}\right.$, molecular weight $265.22 \mathrm{~g} / \mathrm{mol}$ ) was purchased from the Biosharp Co., Ltd).

\section{Ethics statement of animal experiments}

All of the procedures involving mice were carried out in accordance with the Guidelines for the Care and Use of Laboratory Animals prepared by the Institutional Animal Care and Use Committee of Nanjing Agricultural University, Nanjing, China (SYXK(SU)2017-0007). The experimentation was performed in the laboratory animal centre of Nanjing Agricultural University. The method of euthanasia was cervical dislocation.

\section{Experimental animals and diets}

The feeding method of Yu et al. ${ }^{(27)}$ was followed. Sixty male 6-week-old C57BL/6J mice were provided by the Yangzhou University Medical Center; each weighed about $20 \mathrm{~g}$ (the experimental animal production license: SCXK (Su) 201605253). All animals had free access to drinking water and were fed a standard diet for $7 \mathrm{~d}$ and then followed by feeding them with the standard (control) diet or HFD MD1203 (45\% energy from fat) purchased from Medicience Ltd. (Yangzhou, China). The high-fat with a high-sucrose diet is an effective method to induce insulin resistance. The detailed composition of the diet is shown in Table 1 . Mice were housed in plastic cages (five per cage) under standard conditions $\left(20-26^{\circ} \mathrm{C}, 40-70 \%\right.$ relative humidity, $12 \mathrm{~h}$ light-12 h dark cycle). The standard (control) diet was
Table 1. Composition of the high-fat diet

\begin{tabular}{lr}
\hline Name of component & Percentage \\
\hline Casein & 23.31 \\
L-Cysteine & 0.35 \\
Maize starch & $8 \cdot 48$ \\
Malt & 11.65 \\
Sucrose & 20.14 \\
Cellulose & $5 \cdot 83$ \\
Soyabean oil & 2.91 \\
Lard & 20.68 \\
Composite minerals & 5.23 \\
Compound vitamins & 1.16 \\
Choline bitartate & 0.23 \\
Total heat $(\mathrm{kJ} / \mathrm{g})$ & 19.78 \\
\hline
\end{tabular}

Table 2. Construction of experimental mouse model ${ }^{*}$

\begin{tabular}{|c|c|c|c|}
\hline \multicolumn{2}{|l|}{ Standard (control) } & \multicolumn{2}{|l|}{ High fat } \\
\hline Treatments & Time & Treatments & Time \\
\hline Standard (control) diet & 1 week & Standard (control) diet & 1 week \\
\hline Overnight fasting & $12 \mathrm{~h}$ & Overnight fasting & $12 \mathrm{~h}$ \\
\hline Standard (control) diet & 4 weeks & High-fat diet & 4 weeks \\
\hline Citrate acid buffer & 1 week & STZ & 1 week \\
\hline Standard (control) diet & 2 weeks & High-fat diet & 2 weeks \\
\hline Overnight fasting & $12 \mathrm{~h}$ & Overnight fasting & $12 \mathrm{~h}$ \\
\hline $\begin{array}{l}\text { Intra-gastric } \\
\text { administration } \\
\text { (forenoon) }\end{array}$ & 4 weeks & $\begin{array}{l}\text { Intra-gastric } \\
\text { administration } \\
\text { (forenoon) }\end{array}$ & 4 weeks \\
\hline Overnight fasting & $12 \mathrm{~h}$ & Overnight fasting & $12 \mathrm{~h}$ \\
\hline
\end{tabular}

STZ, streptozotocin.

* All mice had unlimited access to drinking water.

provided by the Animal Experimental Center of Nanjing Agricultural University, and its formula is formulated according to the 'Experimental Animal Compound Feed Nutritional Component (GB14924.3-2010)' in the National Standard for Experimental Animal Environment and Facilities (GB149252010). The comparison of nutrients between the standard (control) diet and HFD is shown in online Supplementary Table S1.

\section{Development of high-fat-diet-fed and streptozotocin- treated type 2 diabetic mice}

In order to investigate the alleviation effect of inulin on the type 2 diabetes, mice were fed the HFD and treated with STZ (Table 2). According to a power calculation to determine sample size, the sixty C57BL/6J mice were randomly divided into two groups: the normal control group ( $n$ 10) and the experimental group ( $n$ 50); the normal control group was fed the standard (control) diet, and the experimental group was fed the HFD for 4 weeks. Then the experimental group was injected intraperitoneally with low-dose STZ (50 mg/kg, in citrate buffer, $\mathrm{pH} 4$ 4) for 1 week, whereas the control group mice were given just the same volume of citrate buffer preparation. After another 2 weeks of feeding, all the mice were fasted for $12 \mathrm{~h}$, and the FBG test was carried out by ACCU-CHEK Active (Roche Diagnostics $\mathrm{GmbH})$. FBG $\geq 11.1 \mathrm{mmol} / \mathrm{l}$ is the diagnostic criterion for diabetes. All mice had unlimited access to drinking water. 


\section{Experimental design}

The experimental setup consisted of six different groups. Type 2 diabetic mice were randomly divided into five groups (ten mice per group) and treated daily with intra-gastric administration $(0.2 \mathrm{ml} / 10 \mathrm{~g})$ of each test compound (as described in the previous section) for 4 weeks. The solvent was made with distilled water. Then we fed group CK mice (blank control, standard diet $+5 \mathrm{~g} / \mathrm{kg}$ physiological saline per d) and group $\mathrm{H}$ mice (experimental control group with induced diabetes, standard diet $+5 \mathrm{~g} / \mathrm{kg}$ physiological saline per d) the standard diet, and they received intra-gastric administration of $5 \mathrm{~g} / \mathrm{kg}$ physiological saline ( $0.9 \% \mathrm{NaCl} \mathrm{w} / \mathrm{v})$ per $\mathrm{d}$ for 4 weeks. Group CP mice (positive control group, standard diet + metformin $\mathrm{HCl}$ tablets $125 \mathrm{mg} / \mathrm{kg}$ per d) were fed the standard diet and treated with $125 \mathrm{mg} / \mathrm{kg}$ per d metformin $\mathrm{HCl}$ tablets. Mice in groups LJ (standard diet + inulin $2.5 \mathrm{~g} / \mathrm{kg}$ per d), MJ (standard diet + inulin $5 \mathrm{~g} / \mathrm{kg}$ per d) and $\mathrm{HJ}$ (standard diet + inulin $10 \mathrm{~g} / \mathrm{kg}$ per $\mathrm{d}$ ) were fed the standard diet and treated with, respectively, 2.5, 5 and $10 \mathrm{~g}$ inulin/ $\mathrm{kg}$ per $\mathrm{d}$ (the inulin irrigation amounts were, respectively, 5, 10 and 20 times the recommended daily intake for people) ${ }^{(28)}$.

\section{Determination of weekly body weight and relative liver weight}

The Yu's ${ }^{(27)}$ feeding method was followed. Body weight of each mouse was measured weekly. At the end of the experiment, the relative liver weight per $100 \mathrm{~g}$ of total weight of each mouse was calculated:

\section{Relative liver weight}

$$
=\frac{\text { weight of mice liver }(\mathrm{g})}{\text { body weight on the final experimental day }(\mathrm{g})} \times 100
$$

\section{Blood collection and biochemical assays}

At the end of the 4-week treatment, all the mice were fasted for $12 \mathrm{~h}$ and the FBG test was carried out by ACCU-CHEK Active. The blood samples were collected from the orbital sinus of mice using a 2-ml heparinised syringe and placed on ice for transfer and then centrifuged at $3500 \mathrm{~g}$ at $4^{\circ} \mathrm{C}$ for $15 \mathrm{~min}$ to separate the plasma. The concentrations of total cholesterol, TAG, HDL-cholesterol and LDL-cholesterol in plasma were measured using a Roche MODULAR automatic biochemical analyser at the Integrated Traditional Chinese and Western Medicine Hospital of Nanjing University of Chinese Medicine (Nanjing, China).

\section{Liver collection, total RNA extraction, reverse transcription and real-time $P C R$}

The liver was taken out, fat cleaned and the liver flushed by physiological saline to remove the surface blood at $4^{\circ} \mathrm{C}$. The related gene expression of liver was performed at Shanghai Wcgene Biotech Co. Ltd.

Briefly, to isolate the total RNA, approximately $30 \mathrm{mg}$ of the main lobe from each liver was placed into RNAiso Plus (Takara Co. Ltd), according to the manufacturer's instructions and then resuspended in diethyl pyrocarbonate-treated water. The quality of RNA was assessed by electrophoresis in $1.0 \%(\mathrm{w} / \mathrm{v})$ formaldehyde denaturing agarose gel. Real-time PCR was used to determine mRNA levels based on the Roche FS Universal SYBR Master: 04913914001 instructions in an ABI ViiA7 Real-Time PCR System. A 20- $\mu$ l reaction system contained

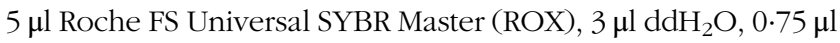
Primer F, $0.75 \mu$ l Primer R, $0.5 \mu$ DNA sample and $10 \mu$ l total volume. The cycling parameters were as follows: $10 \mathrm{~min}$ at $95^{\circ} \mathrm{C}$ followed by one cycle, $30 \mathrm{~s}$ at $95^{\circ} \mathrm{C}$ followed by forty cycles, $30 \mathrm{~s}$ at $60^{\circ} \mathrm{C}$ followed by forty cycles and $10 \mathrm{~min}$ at $72^{\circ} \mathrm{C}$ followed by one cycle.

\section{DNA extraction and intestinal micro-organism communities}

Three replicate mice were randomly selected from each experimental group. Total bacterial DNA from $0.25 \mathrm{~g}$ of colon segment of the large intestine was extracted using a PowerFecal ${ }^{\mathrm{TM}} \mathrm{DNA}$ Isolation kit (MO BIO Laboratories Inc), according to the manufacturer's instructions and was stored at $-80^{\circ} \mathrm{C}$ for further analysis $^{(29)}$. Amplicon pyrosequencing was performed on an Illumina MiSeq platform at Allwegene Technology Inc.

Briefly, DNA was amplified using the $338 \mathrm{~F} / 806 \mathrm{R}$ primer set (338F: 5'-ACTCCTACGGGAGGCAGCAG-3', 806R: $5^{\prime}$-GGACTACHVGGGTWTCTAAT-3') that targets the regions (V3-V4) of the 16S rRNA gene because sequences in those regions provided the greatest diversity at the domain and phylum levels. The PCR was performed in $25-\mu 1$ volume containing $30 \mathrm{ng}$ of DNA template. The cycling parameters were as follows: $5 \mathrm{~min}$ of denaturation at $95^{\circ} \mathrm{C}$ followed by twenty-five cycles of $30 \mathrm{~s}$ at $95^{\circ} \mathrm{C}, 30 \mathrm{~s}$ for annealing at $56^{\circ} \mathrm{C}$ and $40 \mathrm{~s}$ at $72^{\circ} \mathrm{C}$ (elongation), with a final extension at $72^{\circ} \mathrm{C}$ for $10 \mathrm{~min}$. PCR products were processed with an AxyPrep ${ }^{\mathrm{TM}}$ Mag PCR Normaliser kit (Axygen, Inc.) for normalisation.

Quantitative Insights Into Microbial Ecology (https://qiime. org/tutorials/processing_illumina_data.html) quality filters were used to filter the reads ${ }^{(30)}$. We used the Cluster Database at High Identity with Tolerance (CD-HIT) pipeline for picking operational taxonomic units (OTU) and making OTU table. The sequences with similarity of $97 \%$ were assigned to OTU. A representative sequence was selected for each OTU, and the classification data were assigned to each of the representative sequences using the Ribosome Database Project (RDP) classifier $^{(31)}$

To estimate $\alpha$ diversity, the OTU table was rarefied, and four indicators were calculated: Chao 1 estimating richness, the observed OTU as the only OTU counting sample, and Shannon index estimating diversity ${ }^{(32,33)}$. Each sample was classified and statistically analysed using RDP, Greengene and Silva three database comparison ${ }^{(34-36)}$. The sequences obtained were distributed in eight bacterial phyla by RDP (V14 https://rdp.cme.msu.edu/).

Linear discriminant analysis (LDA) and effect size measurement (LEfSe) are common methods for the discovery of macrogenomic biomarkers. We performed LEfSe calculations for the non-parametric Wilcoxon sum-rank test followed by LDA using online software (https://huttenhower.sph.harvard.edu/galaxy/) to assess the effect size of each taxon with differential abundance ${ }^{(37)}$. 
Table 3. Average daily food consumption, body weight, average daily water consumption and relative liver weight as influenced by treating mice for 4 weeks with standard diet and orally with metformin $\mathrm{HCl}$ tablets or intra-gastrically with three different concentrations of inulin (Mean values with their standard errors)

\begin{tabular}{|c|c|c|c|c|c|c|c|c|}
\hline \multirow[b]{2}{*}{ Treatment group } & \multicolumn{2}{|c|}{$\begin{array}{l}\text { Average daily food } \\
\text { consumption }(\mathrm{g} / \mathrm{d})\end{array}$} & \multicolumn{2}{|c|}{$\begin{array}{c}\text { Body weight after } \\
\text { 4-week treatment }(\mathrm{g})\end{array}$} & \multicolumn{2}{|c|}{$\begin{array}{l}\text { Average daily water } \\
\text { consumption }(\mathrm{ml} / \mathrm{d})\end{array}$} & \multicolumn{2}{|c|}{$\begin{array}{c}\text { Relative liver } \\
\text { weight (\%) }\end{array}$} \\
\hline & Mean & SE & Mean & SE & Mean & $\mathrm{SE}$ & Mean & SE \\
\hline $\mathrm{CK} \dagger$ & $3 \cdot 15^{c}$ & 0.12 & $25 \cdot 20^{\mathrm{a}}$ & 0.24 & $3.57^{\mathrm{c}}$ & 0.23 & $4 \cdot 64^{d}$ & 0.11 \\
\hline $\mathrm{H} \ddagger$ & $3 \cdot 15^{c}$ & 0.06 & $23 \cdot 49^{c}$ & 0.23 & $14 \cdot 13^{a}$ & 0.57 & $7 \cdot 35^{\mathrm{a}}$ & 0.36 \\
\hline $\mathrm{CP} \S$ & $4.52^{\mathrm{a}}$ & 0.14 & $24 \cdot 41^{b}$ & 0.18 & $13 \cdot 78^{a}$ & 0.42 & $6 \cdot 11 \mathrm{~b}$ & 0.11 \\
\hline LJII & $4.68^{a}$ & 0.13 & $24.08^{b}$ & 0.21 & $15 \cdot 30^{a}$ & 0.79 & $5.58^{\mathrm{b}, \mathrm{c}}$ & 0.14 \\
\hline MJף & $4.47^{a}$ & 0.11 & $23 \cdot 37^{c}$ & 0.17 & $14 \cdot 31^{a}$ & 0.38 & $5.43^{c}$ & 0.23 \\
\hline$H J^{\star \star}$ & $3.89^{b}$ & 0.15 & $22 \cdot 70^{d}$ & 0.17 & $10 \cdot 58^{b}$ & 0.43 & $5 \cdot 48^{c}$ & 0.14 \\
\hline
\end{tabular}

a,b,c,d Mean values in a column with unlike superscript letters are significantly different $(P \leq 0.05)$.

* Inulin (isolated from Jerusalem artichoke tubers) is a short-chain polymer of fructose molecules containing a high concentration of fructan.

† CK, standard diet + physiological saline of $5 \mathrm{~g} / \mathrm{kg}$ per d (blank control).

$\ddagger \mathrm{H}$, standard diet + physiological saline of $5 \mathrm{~g} / \mathrm{kg}$ per d (experimental control group with induced diabetes).

$\S \mathrm{CP}$, standard diet + metformin $\mathrm{HCl}$ tablets of $125 \mathrm{mg} / \mathrm{kg}$ per $\mathrm{d}$.

II LJ, standard diet + inulin of $2.5 \mathrm{~g} / \mathrm{kg}$ per $\mathrm{d}$.

I $\mathrm{MJ}$, standard diet + inulin of $5 \mathrm{~g} / \mathrm{kg}$ per $\mathrm{d}$.

${ }^{* *} \mathrm{HJ}$, standard diet + inulin of $10 \mathrm{~g} / \mathrm{kg}$ per $\mathrm{d}$.

The complete datasets were deposited in the National Center for Biotechnology Information. The Sequence Read Archive accession number is SRP108873.

\section{Statistical analysis}

Data were analysed by one-way ANOVA using SPSS 19.0 (SPSS Inc.). All data were tested for homogeneity of variance by Levene's test. Tukey's test was then used to compare the differences among the treatments. The level of significance was set at $P \leq 0 \cdot 05$. All data were expressed as means with their standard errors.

\section{Results}

\section{The high-fat-diet-fed and streptozotocin-treated mice} showed type 2 diabetes

No difference in the concentration of FBG was observed between these experimental mice before the induction (online Supplementary Table S2). After the induction of type 2 diabetes (the samples were taken after 2 weeks after diabetes induction), the FBG concentration in the HFD-fed and STZ-treated mice (treatment $\mathrm{H}$, experimental control) increased significantly ( $P \leq 0.05) \quad(\mathrm{FBG} \geq 11.1 \mathrm{mmol} / \mathrm{l}) \quad$ compared with the blank control (CK, standard diet and citrate buffer vehicle) mice. Hence, the treatment with HFD feed and STZ successfully induced type 2 diabetes in mice.

\section{Effect of inulin on average daily food consumption, body} weight, average daily water consumption and relative liver weight in high-fat-diet-fed and streptozotocintreated type 2 diabetic mice

Metformin $\mathrm{HCl}$ tablets (treatment $\mathrm{CP}$, positive control), inulin of $2.5 \mathrm{~g} / \mathrm{kg}$ per $\mathrm{d}$ (treatment $\mathrm{LJ}$ ), inulin of $5 \mathrm{~g} / \mathrm{kg}$ per $\mathrm{d}$ (MJ group) or inulin of $10 \mathrm{~g} / \mathrm{kg}$ per $\mathrm{d}$ (treatment $\mathrm{HJ}$ ) was orally administered to the HFD-fed and STZ-treated type 2 diabeticinduced mice for 4 weeks. Body weight decreased significantly $(P \leq 0.05)$ in the $\mathrm{H}$ (experimental control), $\mathrm{CP}, \mathrm{LJ}, \mathrm{MJ}$ and $\mathrm{HJ}$ groups compared with the $\mathrm{CK}$ group (Table 3 ). Body weight decreased in a dose-dependent way. Average daily food consumption and average daily water consumption were decreased in a dose-dependent manner in the LJ, MJ and $\mathrm{HJ}$ groups (Table 3 ). Compared with the $\mathrm{H}$ group, relative liver weight decreased significantly $(P \leq 0 \cdot 05)$ in the groups treated with metformin $\mathrm{HCl}$ tablets, inulin of $2.5,5$ or $10 \mathrm{~g} / \mathrm{kg}$ per $\mathrm{d}$, but no significant difference was observed between the three groups treated with inulin.

Effect of inulin on serum lipid levels and FBG in high-fatdiet-fed and streptozotocin-treated type 2 diabetic mice

Compared with group $\mathrm{H}$, the serum concentrations of total cholesterol, TAG, HDL-cholesterol and FBG in the CP, LJ, MJ and $\mathrm{HJ}$ groups decreased to a similar degree (between 27 and $70 \%$ ) (Table 4). In the LJ, MJ and HJ groups, the serum concentrations of HDL-cholesterol and FBG decreased in a dose-dependent manner. In contrast, the serum concentration of LDL-cholesterol varied, that is, being the same in the $\mathrm{H}, \mathrm{CP}$, $\mathrm{LJ}$, and $\mathrm{HJ}$ groups but lower in the MJ group compared with the $\mathrm{H}$ group (Table 4).

\section{Liver-related gene expression in hyperglycaemic mice}

As shown in Fig. 1(A) and (B), treatment differences were found in the expression of twenty-two up- and down-regulated genes such as ACAA2, ANKRA2, APOA4, CNBP, COLCE12, CRP, CYP39A1, CYP7B1, LCAT, LDLR, LDLRAP1, LIPE, LRPG, NROB2, NR1H4, NSDHL, OSBPL1A, OSBPL5, SNX17, SOAT2, STAB2 and $T M 7 S F 2$, though the differences were not always significant.

\section{Diversity and richness indices of intestinal microbiota}

Four diversity indices showed a similar trend. The OTU and phylogenetic diversity (PD) whole tree and Shannon indices of the $\mathrm{CP}$ and $\mathrm{HJ}$ groups were significantly different from the LJ treatment group $(P \leq 0.05)$ (Table 5).

The number of OTU was lower in the CP group compared with the other four treatment groups (except HJ, Fig. 2(A)). The distribution of the species did not correspond with an increase in the OTU (Fig. 2(B)). In the Venn diagram, the number 
Table 4. Effect of 4 weeks of the oral treatment with metformin $\mathrm{HCl}$ tablets or the intra-gastric treatment with three different concentrations of inulin on serum lipid levels and fasting blood glucose in experimental mice with induced type 2 diabetes (Mean values with their standard errors)

\begin{tabular}{|c|c|c|c|c|c|c|c|c|c|c|}
\hline \multirow[b]{3}{*}{ Treatment group } & \multicolumn{10}{|c|}{ Concentration $(\mathrm{mmol} / \mathrm{l})$} \\
\hline & \multicolumn{2}{|c|}{$\begin{array}{c}\text { Total } \\
\text { cholesterol } \\
\end{array}$} & \multicolumn{2}{|c|}{ TAG } & \multicolumn{2}{|c|}{ HDL-cholesterol } & \multicolumn{2}{|c|}{$\underline{\text { LDL-cholesterol }}$} & \multicolumn{2}{|c|}{$\begin{array}{l}\text { Fasting blood } \\
\text { glucose }\end{array}$} \\
\hline & Mean & SE & Mean & SE & Mean & SE & Mean & SE & Mean & SE \\
\hline $\mathrm{CK}^{*}$ & $2 \cdot 03^{c}$ & 0.08 & $1.01^{\mathrm{b}}$ & 0.05 & $1.89^{c}$ & 0.05 & $0.32^{\mathrm{c}}$ & 0.03 & $7.09^{c, d}$ & 0.19 \\
\hline $\mathrm{H} \dagger$ & $4 \cdot 40^{\mathrm{a}}$ & 0.28 & $2 \cdot 69^{a}$ & 0.21 & $2 \cdot 81^{a}$ & 0.18 & $0.99^{a}$ & 0.11 & $17 \cdot 62^{a}$ & 1.09 \\
\hline $\mathrm{CP} \ddagger$ & $3 \cdot 12^{b}$ & 0.13 & $1 \cdot 15^{\mathrm{b}}$ & 0.07 & $2 \cdot 28^{\mathrm{b}}$ & 0.12 & $0.91^{\mathrm{a}}$ & 0.04 & $10 \cdot 19^{b}$ & 0.96 \\
\hline LJ§ & $2.99^{b}$ & 0.10 & $1.23^{b}$ & 0.09 & $2 \cdot 26^{b}$ & 0.04 & $0.80^{a, b}$ & 0.04 & $11.39^{b}$ & 1.31 \\
\hline MJII & $2 \cdot 86^{b}$ & 0.18 & $1.21^{\mathrm{b}}$ & 0.06 & $2 \cdot 12^{\mathrm{b}, \mathrm{c}}$ & 0.12 & $0.69^{b}$ & 0.07 & $9.55^{b, c}$ & 1.06 \\
\hline HJף & $2 \cdot 78^{\mathrm{b}}$ & 0.07 & $1.01^{\mathrm{b}}$ & 0.05 & $1.95^{\mathrm{c}}$ & 0.03 & $0.93^{\mathrm{a}}$ & 0.07 & $5 \cdot 29^{d}$ & 0.38 \\
\hline
\end{tabular}

a,b,c,d Mean values in a column with unlike superscript letters are significantly different $(P \leq 0.05)$.

${ }^{*} \mathrm{CK}$, standard diet + physiological saline of $5 \mathrm{~g} / \mathrm{kg}$ per d (blank control).

$\dagger \mathrm{H}$, standard diet + physiological saline of $5 \mathrm{~g} / \mathrm{kg}$ per $\mathrm{d}$ (experimental control group with induced diabetes).

‡ CP, standard diet + metformin $\mathrm{HCl}$ tablets of $125 \mathrm{mg} / \mathrm{kg}$ per $\mathrm{d}$.

$\S \mathrm{LJ}$, standard diet + inulin of $2.5 \mathrm{~g} / \mathrm{kg}$ per $\mathrm{d}$.

II MJ, standard diet + inulin of $5 \mathrm{~g} / \mathrm{kg}$ per $\mathrm{d}$.

ๆ $\mathrm{HJ}$, standard diet + inulin of $10 \mathrm{~g} / \mathrm{kg}$ per $\mathrm{d}$

(A)

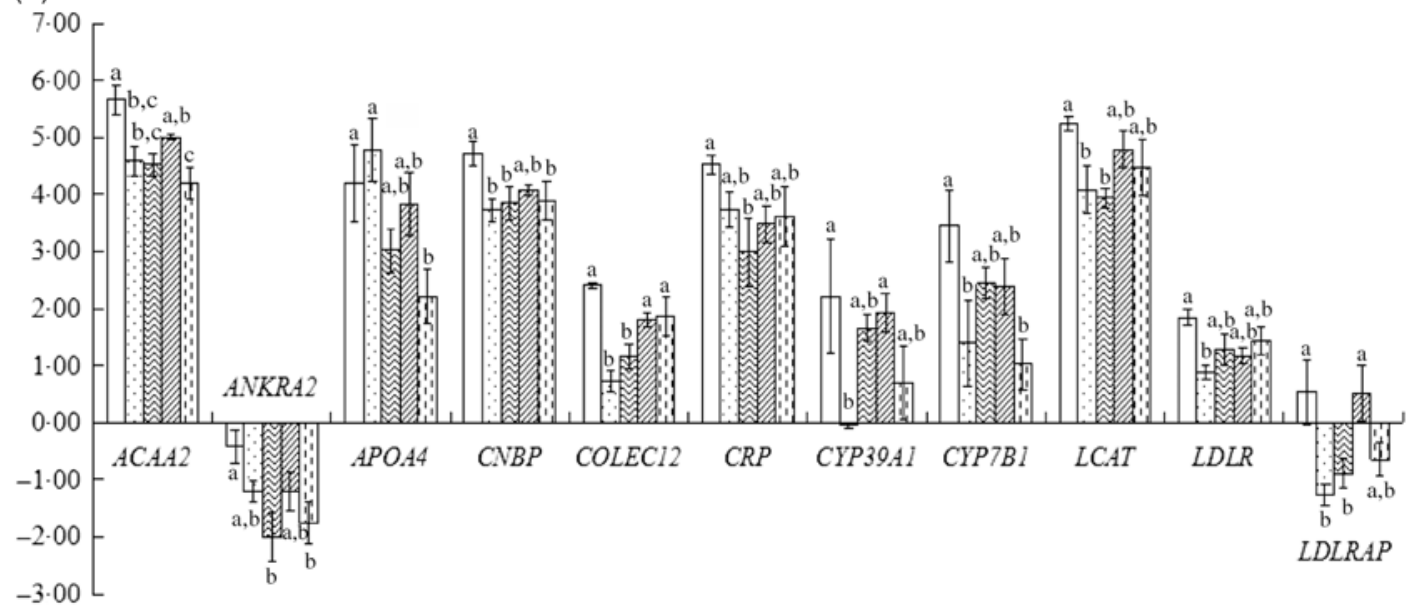

(B)

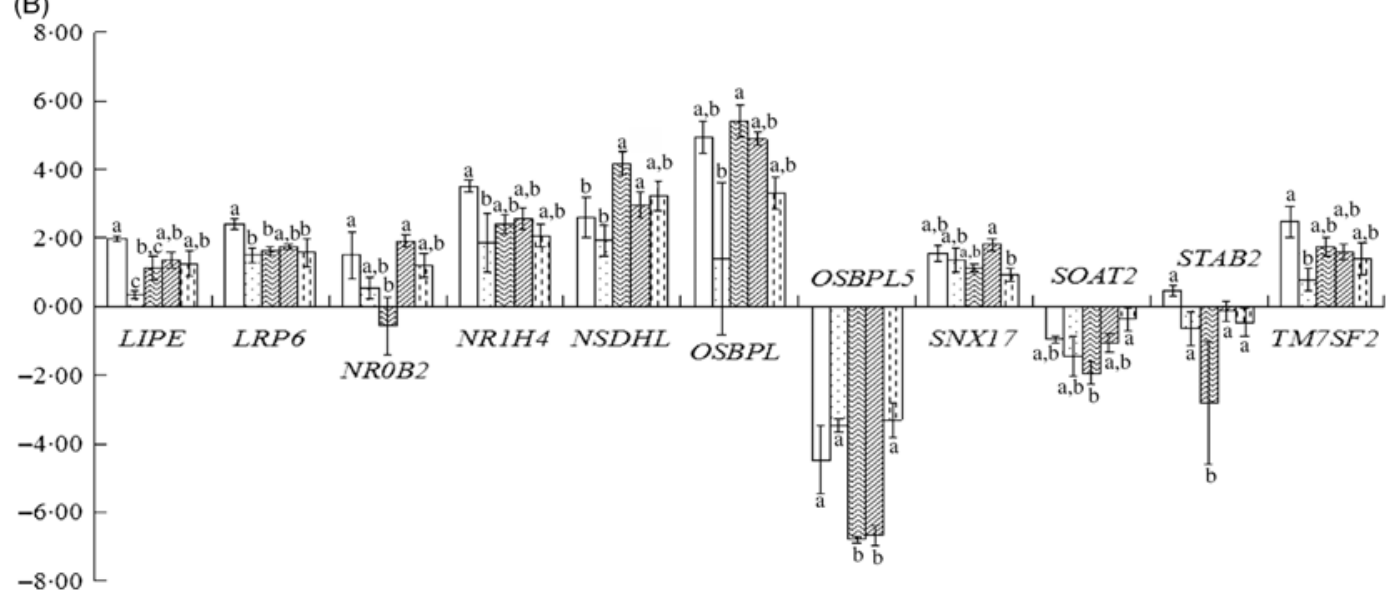

Fig. 1. Liver-related gene expression in hyperglycaemic mice. (A) and (B) Liver-related gene expression. CK, standard diet + physiological saline of $5 \mathrm{~g} / \mathrm{kg}$ per $\mathrm{d}$ (blank control); $\mathrm{H}$, standard diet + physiological saline of $5 \mathrm{~g} / \mathrm{kg}$ per d (experimental control group with induced diabetes); $\mathrm{CP}$, standard diet $+\mathrm{metformin} \mathrm{HCl}$ tablets of $125 \mathrm{mg} / \mathrm{kg}$ per d; LJ, standard diet + inulin of $2.5 \mathrm{~g} / \mathrm{kg}$ per d; HJ, standard diet + inulin of $10 \mathrm{~g} / \mathrm{kg}$ per d. ${ }^{\mathrm{a}, \mathrm{b}, \mathrm{c}}$ Mean values for a gene with unlike letters are significantly different $(P<0.05) . \square, \mathrm{CK} ; \square, \mathrm{H}$; ब, CP; 四, LJ; 四, HJ. 
Table 5. Comparison of estimated operational taxonomic unit (OTU) richness and diversity indices ( $\alpha$ diversity index) of the mouse intestinal 16S rDNA gene libraries for clustering at $97 \%$ identity as obtained from pyrosequencing analysis

(Mean values with their standard errors)

\begin{tabular}{lcccc}
\hline & Chao 1 index & OTU & $\begin{array}{c}\text { PD whole tree } \\
\text { index }\end{array}$ & Shannon index \\
\hline CK $^{\star}$ & $268^{\mathrm{a}, \mathrm{b}}$ & $239^{\mathrm{a}, \mathrm{b}}$ & $18 \cdot 8^{\mathrm{a}, \mathrm{b}}$ & $5 \cdot 53^{\mathrm{a}, \mathrm{b}}$ \\
$\mathrm{H \dagger}$ & $255^{\mathrm{a}, \mathrm{b}}$ & $234^{\mathrm{a}, \mathrm{b}}$ & $19 \cdot 4^{\mathrm{a}, \mathrm{b}}$ & $5 \cdot 78^{\mathrm{a}}$ \\
$\mathrm{CP} \ddagger$ & $226^{\mathrm{b}}$ & $188^{\mathrm{b}}$ & $16 \cdot 6^{\mathrm{b}}$ & $4 \cdot 87^{\mathrm{b}, \mathrm{c}}$ \\
LJ§ & $299^{\mathrm{a}}$ & $267^{\mathrm{a}}$ & $21 \cdot 1^{\mathrm{a}}$ & $5 \cdot 67^{\mathrm{a}}$ \\
$\mathrm{HJII}$ & $238^{\mathrm{a}, \mathrm{b}}$ & $201^{\mathrm{b}}$ & $17 \cdot 3^{\mathrm{b}}$ & $4 \cdot 73^{\mathrm{c}}$ \\
\hline
\end{tabular}

$\mathrm{PD}$, Phylogenetic diversity.

$\mathrm{a}, \mathrm{b}, \mathrm{c}$ Mean values in a column with unlike superscript letters are significantly different $(P \leq 0.05)$.

* CK, standard diet + physiological saline of $5 \mathrm{~g} / \mathrm{kg}$ per d (blank control).

$\dagger \mathrm{H}$, standard diet + physiological saline of $5 \mathrm{~g} / \mathrm{kg}$ per d (experimental control group with induced diabetes)

$\ddagger \mathrm{CP}$, standard diet + metformin $\mathrm{HCl}$ tablets of $125 \mathrm{mg} / \mathrm{kg}$ per $\mathrm{d}$.

$\S \mathrm{LJ}$, standard diet + inulin of $2.5 \mathrm{~g} / \mathrm{kg}$ per $\mathrm{d}$.

II HJ, standard diet + inulin of $10 \mathrm{~g} / \mathrm{kg}$ per d.

(A)

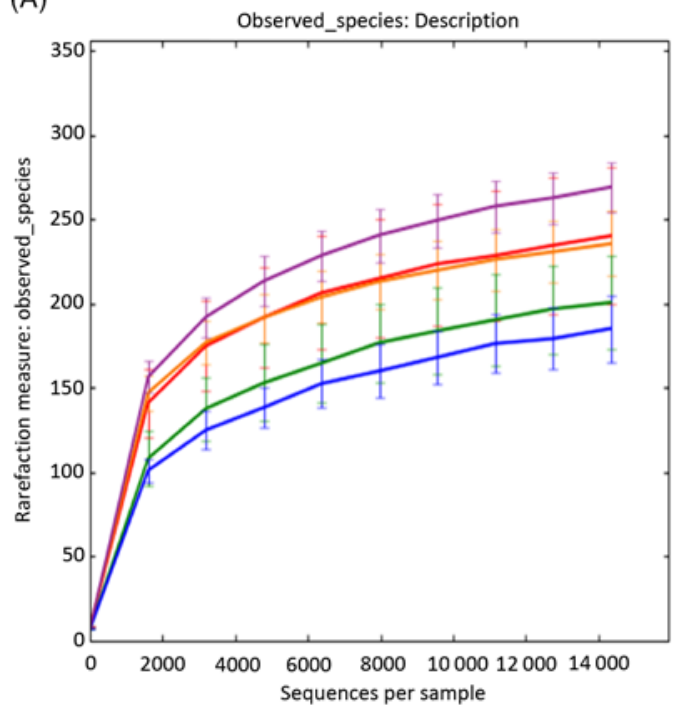

of unique sequences was largest in the CK (20) and smallest in $\mathrm{CP}$ (1) groups, and 159 in common among the five treatment groups (Fig. 2(C) $)^{(38)}$.

\section{Statistical analysis of species classification}

In general, bacterial composition of different samples was similar with regard to the phyla present but varied in the distribution of each phylum (Fig. 3). The sequences obtained were distributed by RDP in sixty-one bacterial taxa. In general, bacterial composition of different samples was similar with regard to the taxa present but varied in the distribution of each taxon (Fig. 4). Unidentified and others represented a large proportion in all groups, accounting for more than $45 \%$ of the reads. Compared with the CK group, the H group had significantly higher proportions of Incertae sedis, Allobaculum, Helicobacter, Dorea, Intestinimonas, Bilophila, RC9 gut group, Anaerotruncus, Akkermansia, Roseburia, Oscillibacter,

(B)

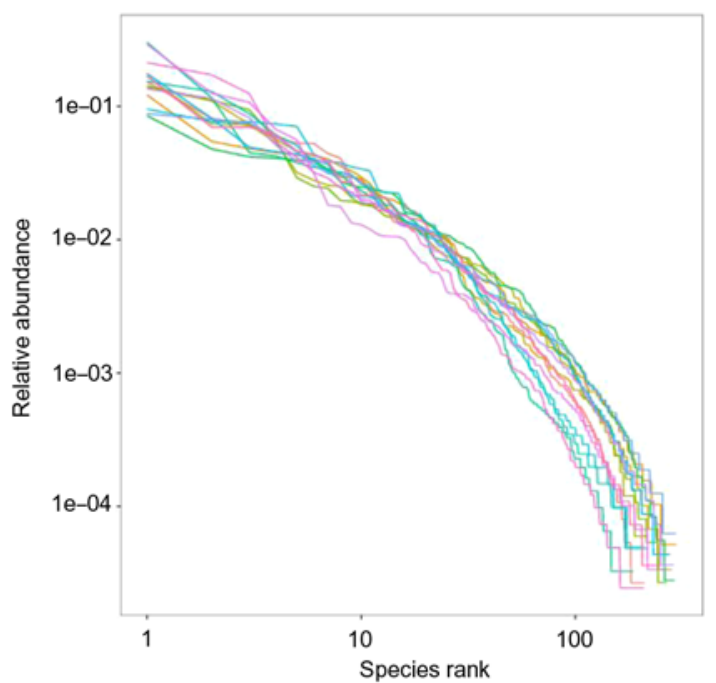

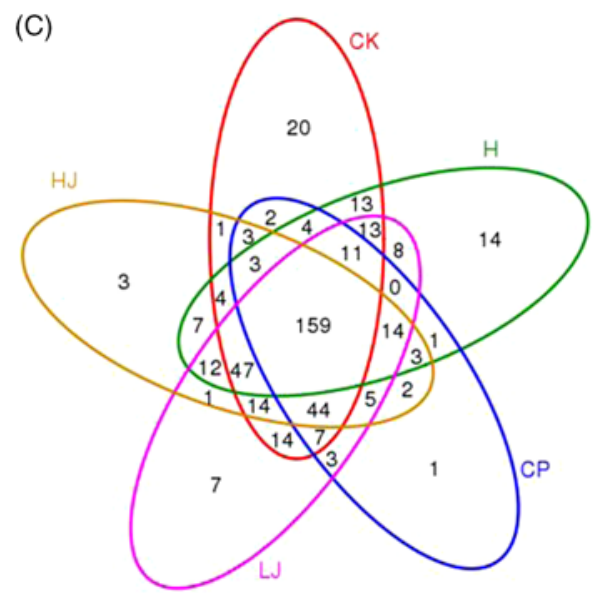

Fig. 2. (A) Rarefaction curves showing the observed species (operational taxonomic units; OTU) richness (97\% identity) of the $16 \mathrm{~S}$ rDNA gene with increasing sequencing depth. (B) Rank abundance curves showing the richness and evenness of the observed species (97\% identity) based on the $16 \mathrm{~S}$ rDNA gene. (C) Venn diagram depicting OTU of bacteria detected in mice intestinal contents as influenced by the treatments. CK, standard diet + physiological saline of $5 \mathrm{~g} / \mathrm{kg}$ per $\mathrm{d}(\mathrm{blank}$ control); $\mathrm{H}$, standard diet + physiological saline of $5 \mathrm{~g} / \mathrm{kg}$ per d (experimental control group); CP, standard diet + metformin $\mathrm{HCl}$ tablets of $125 \mathrm{mg} / \mathrm{kg}$ per d; LJ, standard

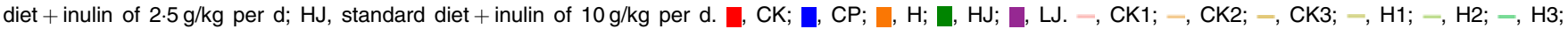
,$- \mathrm{CP} 1 ;-, \mathrm{CP} 2 ;-, \mathrm{CP} 3 ;-, \mathrm{LJ} 1 ;-, \mathrm{LJ} 2 ;-, \mathrm{LJ} 3 ;-, \mathrm{HJ} 1 ;-, \mathrm{HJ} 2 ;-, \mathrm{HJ} 3$. 


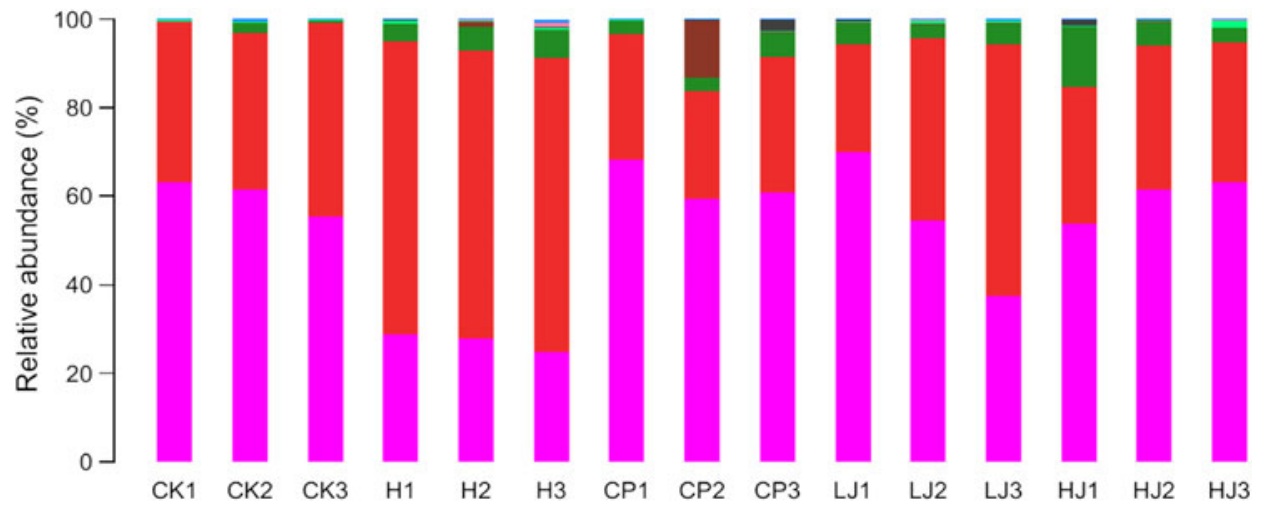

Fig. 3. Relative abundance of the dominant bacterial phyla in mouse intestinal contents as influenced by the treatments. The relative abundances are based on the proportional frequencies of DNA sequences that could be classified at the phylum level. CK, standard diet + physiological saline of $5 \mathrm{~g} / \mathrm{kg}$ per $\mathrm{d}$ (blank control); $\mathrm{H}$, standard diet + physiological saline of $5 \mathrm{~g} / \mathrm{kg}$ per d (experimental control group); $\mathrm{CP}$, standard diet + metformin HCl tablets of $125 \mathrm{mg} / \mathrm{kg} \mathrm{per} \mathrm{d;} \mathrm{LJ,} \mathrm{standard} \mathrm{diet} \mathrm{+}$ inulin of $2.5 \mathrm{~g} / \mathrm{kg}$ per d; HJ, standard diet + inulin of $10 \mathrm{~g} / \mathrm{kg}$ per d. $\square, \quad \mathrm{p} \_$B Bacteroidetes; $\square, \quad \mathrm{p} \_$Firmicutes; $\square, \quad \mathrm{p} \_$Proteobacteria; $\square, \mathrm{p} \_$Verrucomicrobia; $\square, \mathrm{p} \_$Actinobacteria; $\square, \mathrm{p} \_$_Cyanobacteria; $\square, \mathrm{p} \_$Candidate_division_TM7; $\square$, other.

Lactobacillus and Desulfovibrio $(1 \cdot 5,3 \cdot 5,2 \cdot 7,22,2 \cdot 8,24,3 \cdot 2$, $7 \cdot 2,12,6 \cdot 2,4 \cdot 1,1 \cdot 2$ and 114 times respectively) and lower proportions of Bacteroides, Blautia, Alistipes, Odoribacter, Parabacteroides and Coprococcus (0.49, 0.85, 0.90, 0.60, 0.32 and 0.48 respectively). Compared with the $\mathrm{H}$ group, the inulin treatment $\mathrm{LJ}$ and $\mathrm{HJ}$ groups had significantly higher proportions of Bacteroides (2.4 and 9.1 times, respectively), Blautia (2.0 and 1.7 times, respectively), Incertae sedis (2.1 and 3.3 times, respectively), Helicobacter ( 0.9 and 3.1 times, respectively), Alistipes ( 1.0 and 1.1 times, respectively), Bilophila (1.2 and 1.0 times, respectively), Parabacteroides (3.3 and 4.4 times, respectively) and RC9 gut group (1.7 and 1.9 times, respectively) and lower proportions of Allobaculum (0.02 and 0.02, respectively), Dorea (0.03 and $0 \cdot 08$, respectively), Odoribacter ( 0.49 and 0.54 , respectively), Intestinimonas (0.11 and 0.08, respectively), Anaerotruncus ( $0 \cdot 18$ and 0.08, respectively), Akkermansia (0.29 and 0.19, respectively), Roseburia (0.03 and 0.01 , respectively), Oscillibacter (0.05 and 0.02, respectively), Lactobacillus (0.12 and 0.32, respectively), Coprococcus (0.60 and 0.26, respectively) and Desulfovibrio (0.01 and 0.02, respectively).

We used LEfSe, a statistical tool designed to find biomarkers in the metagenome data with default parameters, to identify potential discriminating taxa among treatments. LEfSe was performed to obtain the cladogram representation and the predominant bacteria in the intestinal microbiota in the control $(\mathrm{CK})$ and four treatment groups $(\mathrm{H}, \mathrm{CP}, \mathrm{LJ}$ and $\mathrm{HJ}$; online Supplementary Fig. S1(A)). Online Supplementary Fig. S1(B) shows the largest differences in taxa among the four communities. On a genus level, Incertae sedis was enriched in the CK group, Dorea, Roseburia, Anaerotruncus, Oscillibacter, Allobaculum, Candidate division TM7, Streptococcus, Candidatus Saccharimonas, Acetatifactor, Mucispirillum, Peptococcus, Anaerovorax, Turicibacter and Clostridium sensu stricto 1 were enriched in the H group; Bacteroides, Anaerostipes and Morganella were enriched in the CP group; Acaligenes, Ruminococcus, Paenalcaligenes, Wautersiella and Flavonifractor were enriched in the LJ group, whereas
Incertae sedis and Subdoligranulum were enriched in the HJ group.

\section{Discussion}

According to previous studies, inulin improved insulin secretion, the damaged liver and reduced the levels of blood glucose, serum cholesterol and TAG in the STZ-treated mice with induced diabetes ${ }^{(39)}$. Studies have shown that inulin can increase the number of beneficial bacteria, such as bifidobacteria, lactobacilli and certain butyrate-producing bacteria in the colon, and reduce the population of the harmful bacteria from the Clostridium perfringens group ${ }^{(40,41)}$. Similarly, research showed that inulin can improve the levels of cholesterol, blood fat and blood sugar ${ }^{(42)}$. However, the hypoglycaemic effect of inulin needs to be studied in more detail, and the potential mechanisms remain to be determined.

In the $\mathrm{HJ}$ group, mice treated with inulin showed a decrease in body weight (Table 3). A hyperglycaemic mouse model was fed the HFD in combination with STZ treatment. After 4 weeks of treatment, the weight of the HJ group was significantly lower compared with the $\mathrm{H}$ group $(P \leq 0.05)$ and the weight of the inulin-treated group (LJ and MJ groups). It showed a significant downward trend and a dose dependency. However, compared with the $\mathrm{H}$ group, the daily average feed consumption of the $\mathrm{CP}, \mathrm{LJ}, \mathrm{MJ}$ and $\mathrm{HJ}$ groups increased significantly $(P \leq 0.05)$. This phenomenon indicates that although the daily consumption of the feed increased after the Jerusalem artichoke inulin treatment, the body weight did not increase. Compared with the H group, the relative liver weight and daily average drinking water consumption of the CP, LJ, MJ and HJ groups were reduced, though this reduction may not be significant, and the higher the relative liver weight ratio, the higher the utilisation of fat components in the feed ${ }^{(43)}$. Such a result was unlikely caused by appetite suppression; on the contrary, the energy consumption of inulin-treated animals may increase. Relative liver weight decreased significantly $(P \leq 0.05)$ in the treatment groups 

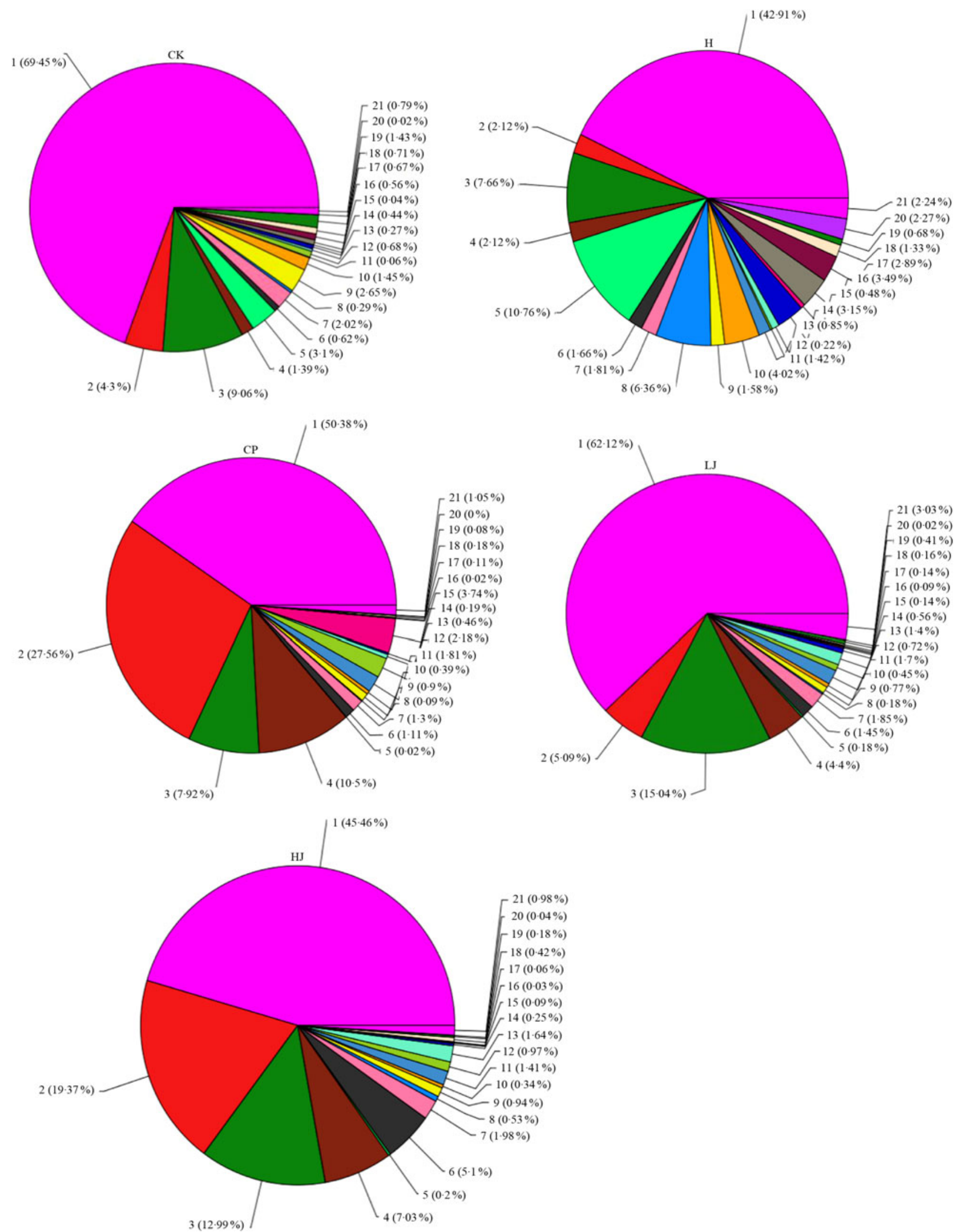

Fig. 4. Percentage of different bacterial families in each sample. Data are expressed as means $(n 3)$. Sequences that could not be classified into any known groups were labelled 'other'. CK, standard diet + physiological saline of $5 \mathrm{~g} / \mathrm{kg}$ per d (blank control); $\mathrm{H}$, standard diet + physiological saline of $5 \mathrm{~g} / \mathrm{kg}$ per d (experimental control group); $\mathrm{CP}$, standard diet + metformin $\mathrm{HCl}$ tablets of $125 \mathrm{mg} / \mathrm{kg}$ per d; LJ, standard diet + inulin of $2.5 \mathrm{~g} / \mathrm{kg}$ per d; HJ, standard diet + inulin of $10 \mathrm{~g} / \mathrm{kg}$ per d. 1: g_unidentified; 2: g_Bacteroides; 3: g_Blautia; 4: g_Incertae_Sedis; 5: g_Allobaculum; 6: g_Helicobacter; 7: g_Alistipes; 8: g_Dorea; 9: g_Odoribacter; 10: g_Intestinimonas; 11: g_Bilophila; 12: g_Parabacteroides; 13: g_RC9_gut_group; 14: g_Anaerotruncus; 15: g_Akkermansia; 16: g__Roseburia; 17: g__Oscillibacter; 18: g_L_Lactobacillus; 19: g__Coprococcus; 20: g_Desulfovibrio; 21: other. 
compared with the $\mathrm{H}$ group (Table 3). A high relative ratio of liver weight shows significant amounts of fat deposited in the liver ${ }^{(39)}$.

Importantly, inulin was more effective than metformin $\mathrm{HCl}$ tablets in decreasing total cholesterol levels in hyperglycaemic mice (Table 4). The FBG and serum lipid levels in the mice of the Jerusalem artichoke inulin group were significantly reduced and show a dose-dependent relation compared with hyperglycaemic (H group) mice. Similarly, the levels of total cholesterol, TAG and HDL-cholesterol in the serum of the Jerusalem artichoke inulin-treated group (LJ, MJ and HJ groups) were significantly lower than those in the hyperglycaemic group (group $\mathrm{H}$ ) and show a dose-dependent relation. It indicated that Jerusalem artichoke inulin can reduce the FBG levels in hyperglycaemic mice and alleviate the abnormal blood lipid index caused by diabetes in hyperglycaemic mice (Table 4). Inulin decreased serum cholesterol and TAG concentrations, which is consistent with the previous findings ${ }^{(44)}$.

In total, forty-nine genes were up-regulated and thirty-five were down-regulated. Among the up-regulated and downregulated ones, treatment differences were found in the expression of twenty-two genes including $L D L R, L D L R A P 1$, LRPG, STAB2 and ANKRA2 as the LDL receptors ${ }^{(45,46)}$. $A P O A 4$ is an LDL-related protein and is associated with cholesterol efflux, reversed cholesterol transport and cholesterol homoeostasis ${ }^{(47,48)}$. CYP39A1 is related to cholesterol catabolism $^{(49)}$. TM7SF2, NSDHL and ACAA2 are related to cholesterol biosynthesis ${ }^{(50,51)}$ and $C Y P 7 B 1$ to cholesterol metabolism $^{(52)}$. LCAT is involved in HDL metabolism ${ }^{53)}$.

The results of $16 \mathrm{~S}$ rDNA gene sequencing indicated that the use of a HFD and STZ could change the composition of the intestinal microbiota of mice (online Supplementary Fig. S2). The mice intestinal microbiota improved (online Supplementary Figs. S3, S4 and S5) when treated with metformin $\mathrm{HCl}$ tablets, and a similar result was achieved with the Jerusalem artichoke inulin treatment. In particular, the inulin treatment increased intestinal abundance of Bacteroidetes and reduced intestinal abundance of Firmicutes (Fig. 3). These findings were consistent with the previous studies of inulin changing the abundance of intestinal bacteria. In the present study, the abundance of Bacteroides in the $\mathrm{H}$ treatment group was only 0.49 times that of the CK group. This is consistent with the published literature ${ }^{(54,55)}$. In contrast, the abundance of Lactobacillus in the $\mathrm{H}$ treatment group was 1.9 times that of the CK group. Lactobacillus is a type of 'friendly' bacteria that normally live in our digestive, urinary and genital systems, without causing disease. Lactobacillus is used for treating and preventing diarrhoea and it is also used to treat high cholesterol, skin disorders, lactose intolerance, Lyme disease and hives and to boost the immune system ${ }^{(56)}$. Bacteroides is the predominant genus within the lower human intestinal tract, as evidenced by its prevalence in the product of this open-ended culture system, faeces. Within the intestinal tract, Bacteroides spp. host molecular interaction can influence host function, for example, in relation to immune system development ${ }^{(57)}$. Compared with the $\mathrm{H}$ group, the abundance of Bacteroides in the $\mathrm{LJ}$ and $\mathrm{HJ}$ inulin treatment groups increased significantly (2.4 and 9.1 times, respectively) (Fig. 4), which is consistent with the published results ${ }^{(58)}$.

\section{Conclusions}

Jerusalem artichoke inulin reduced the levels of FBG and blood lipids in a dose-dependent manner and showed the antihyperglycaemic effects in mice fed the HFD and those treated with STZ. After the treatment with inulin, the expression of liver-related genes changed in the hyperglycaemic mice, and the proportion of Bacteroides in the intestinal tract of hyperglycaemic mice increased significantly. Jerusalem artichoke inulin may alleviate diabetes and increase the beneficial intestinal microbiota of HFD-fed hyperglycaemic mice and STZ-treated hyperglycaemic mice. Jerusalem artichoke inulin may be useful as a functional food ingredient in the prevention and/or treatment of hyperglycaemia.

\section{Acknowledgements}

The authors highly appreciate Professor Zed Rengel in the University of Western Australia for assisting with the English polishing of this manuscript.

The present study was supported by the National Key Research and Development Program of China (2016YFC0501207), the National Key Project of Scientific and Technical Supporting Programs funded by the Ministry of Science \& Technology of Jiangsu Province (BE2018387, BY2016077-02 and BN2016145) and the Fundamental Research Funds for the Central University (KYZ201623, YZ2016-1 and KYYJ201703).

The authors' contributions are as follows: Q. Y., X. L. and Z. L. designed the experiments. T. S., Q. Y., T. Z., A. L. and X. G. performed the experiments. T. S., Q. Y. and X. L. analysed the data. Q. Y., T. S. and X. L. wrote the manuscript. All authors have read and approved the final version of the manuscript.

The authors have no financial or personal conflicts of interests to declare.

\section{Supplementary material}

To view supplementary material for this article, please visit https://doi.org/10.1017/S0007114519002332

\section{References}

1. Grundy SM, Benjamin IJ, Burke GL, et al. (1999) Diabetes and cardiovascular disease: a statement for healthcare professionals from the American Heart Association. Circulation 100, 1134-1146.

2. Wild S, Roglic G, Green A, et al. (2004) Global prevalence of diabetes estimates for the year 2000 and projections for 2030. Diabetes Care 27, 1047-1053.

3. Wellen KE \& Hotamisligil GS (2005) Inflammation, stress, and diabetes. J Clin Invest 115, 1111-1119.

4. Andallu B, Suryakantham V, Srikanthi BL, et al. (2001) Effect of mulberry (Morus indica L.) therapy on plasma and erythrocyte membrane lipids in patients with type 2 diabetes. Clin Chim Acta 314, 47-53.

5. Sheu WH, Jeng CY, Lee WJ, et al. (2011) Simvastatin treatment on postprandial hypertriglyceridemia in type 2 diabetes mellitus patients with combined hyperlipidemia. Metabolism 50, 355-359. 
6. Gentile S, Turco S, Guarino G, et al. (2000) Comparative efficacy study of atorvastatin vs. simvastatin, pravastatin, lovastatin and placebo in type 2 diabetic patients with hypercholesterolaemia. Diabetes Obes Metab 2, 355-362.

7. Farhangi MA, Keshavarz SA, Eshraghian M, et al. (2013) White blood cell count in women: relation to inflammatory biomarkers, haematological profiles, visceral adiposity, and other cardiovascular risk factors. J Health Popul Nutr 31, 58-64.

8. Leevy CM, Ryan CM \& Fineberg JC (1950) Diabetes mellitus and liver dysfunction: etiologic and therapeutic considerations. $\mathrm{Am}$ J Med 8, 290-299.

9. Cani PD, Bibiloni R, Knauf C, et al. (2008) Changes in gut microbiota control metabolic endotoxemia-induced inflammation in high-fat diet-induced obesity and diabetes in mice. Diabetes $\mathbf{5 7}$, 1470-1481.

10. Burcelin R, Serino M, Chabo C, et al. (2011) Gut microbiota and diabetes: from pathogenesis to therapeutic perspective. Acta Diabetol 48, 257-273.

11. Suganami T, Mieda T, Itoh M, et al. (2007) Attenuation of obesity-induced adipose tissue inflammation in $\mathrm{C} 3 \mathrm{~h} / \mathrm{Hej}$ mice carrying a toll-like receptor 4 mutation. Biochem Biophys Res Commun 354, 45-49.

12. Kolid S \& Gibson GR (2007) Prebiotic capacity of inulin-type fructans. J Nutr 137, 2503S.

13. Cani PD, Neyrinck AM, Fava F, et al. (2007) Selective increases of bifidobacteria in gut microbiota improve high-fat-dietinduced diabetes in mice through a mechanism associated with endotoxaemia. Diabetologia 50, 2374-2383.

14. Cani PD, Possemiers S, Van de Wiele T, et al. (2009) Changes in gut microbiota control inflammation in obese mice through a mechanism involving Glp-2-driven improvement of gut permeability. Gut 8, 1091-1103.

15. Dewulf EM, Cani PD, Claus SP, et al. (2013) Insight into the prebiotic concept: lessons from an exploratory, double blind intervention study with inulin-type fructans in obese women. Gut 62, 1112-1121.

16. Everard A, Belzer C, Geurts L, et al. (2013) Cross-talk between Akkermansia muciniphila and intestinal epithelium controls diet-induced obesity. Proc Natl Acad Sci U S A 110, 9066-9071.

17. Everard A, Lazarevic V, Derrien M, et al. (2011) Responses of gut microbiota and glucose and lipid metabolism to prebiotics in genetic obese and diet-induced leptin-resistant mice. Diabetes 60, 2775-2786.

18. Eizirik DL, Pipeleers DG, Ling Z, et al. (1994) Major species differences between humans and rodents in the susceptibility to pancreatic beta-cell injury. Proc Natl Acad Sci U S A 91, 9253-9256.

19. Schnedl WJ, Ferber S, Johnson JH, et al. (1994) STZ transport and cytotoxicity. Specific enhancement in GLUT2- expressing cells. Diabetes 43, 1326-1333.

20. Srinivasan K, Viswanad B, Asrat L, et al. (2005) Combination of high-fat diet-fed and low-dose streptozotocin-treated rat: a model for type 2 diabetes and pharmacological screening. Pharmacol Res 52, 313-320.

21. Cuesta G, Suarez N, Bessio MI, et al. (2003) Quantitative determination of pneumococcal capsular polysaccharide serotype 14 using a modification of phenol-sulfuric acid method. J Microbiol Methods 52, 69-73.

22. Waes CV, Baert J, Carlier L, et al. (1998) A rapid determination of the total sugar content and the average inulin chain length in roots of chicory (Cichorium intybus L). J Sci Food Agr 76, 107-110.

23. Stepensky D, Friedman M, Raz I, et al. (2002) Pharmacokineticpharmacodynamic analysis of the glucose-lowering effect of metformin in diabetic rats reveals first-pass 28 . World Health
Organization WHO. 1990. Diet, nutrition and the prevention of chronic disease. WHO Tech Rep Ser 797, 201-226.

24. Burton JH, Johnson WD \& Greenway FL (2016) Ethyl cellulose microparticles containing metformin $\mathrm{HCl}$ by emulsificationsolvent evaporation technique: effect of formulation variables. ISRN Polymer Sci 2012, 29-35.

25. Oh TO, Kim JY, Ha JM, et al. (2013) Preparation of highly porous gastroretentive metformin tablets using a sublimation method. Eur J Pharm Biopharm 83, 460-467.

26. Nayaka AK \& Pal D (2013) Formulation optimization and evaluation of jackfruit seed starch-alginate mucoadhesive beads of metformin HCl. Int J Biol Macromol 59, 264-272.

27. $\mathrm{Yu} \mathrm{QH}$, Zhao JJ, Xu ZK, et al. (2018) Inulin from Jerusalem artichoke tubers alleviates hyperlipidemia and increases abundance of bifidobacteria in the intestines of hyperlipidemic mice. J Funct Foods 40, 187-196.

28. WHO (1990) Diet, nutrition and the prevention of chronic disease. WHO Tech Rep Ser 797, 201-226.

29. Rodrigues JLM, Pellizari VH, Mueller R, et al. (2013) Conversion of the Amazon rainforest to agriculture results in biotic homogenization of soil bacterial communities. Proc Natl Acad Sci U S A 110, 988-993.

30. Schloss PD, Gevers D \& Westcott SL (2011) Reducing the effects of PCR amplification and sequencing artifacts on $16 \mathrm{~S}$ rRNA-based studies. PLOS ONE 6, e27310.

31. Caporaso JG, Gordon JI, Walters WA, et al. (2011) Global patterns of $16 \mathrm{~S}$ rRNA diversity at a depth of millions of sequences per sample. Proc Natl Acad Sci US A 108, 4516-4522.

32. Kuffner M, Hai B, Rattei T, et al. (2012) Effects of season and experimental warming on the bacterial community in a temperate mountain forest soil assessed by $16 \mathrm{~S}$ rRNA gene pyrosequencing. FEMS Microbiol Ecol 82, 551-562.

33. Vishnivetskaya TA, Mosher JJ, Palumbo AV, et al. (2011) Mercury and other heavy metals influence bacterial community structure in contaminated Tennessee streams. Appl Environ Microbiol 77, 302-311.

34. Cole JR, Wang Q, Cardenas E, et al. (2009) The Ribosomal Database Project: improved alignments and new tools for rRNA analysis. Nucleic Acids Res 37, 141-145.

35. DeSantis TZ, Hugenholtz P, Larsen N, et al. (2006) Greengenes, a chimera-checked 16S rRNA gene database and workbench compatible with ARB. Appl Environ Microbiol 72, 5069-5072.

36. Quast C, Pruesse E, Yilmaz P, et al. (2013) The SILVA ribosomal RNA gene database project: improved data processing and web-based tools. Nucleic Acids Res 41, 590-596.

37. Segata N, Izard J, Waldron L, et al. (2011) Metagenomic biomarker discovery and explanation. Genome Biol 12, R60.

38. Fouts DE, Szpakowski S, Purushe J, et al. (2012) Next generation sequencing to define prokaryotic and fungal diversity in the bovine rumen. PLOS ONE 7, e48289.

39. Soni NK, Nookaew I, Sandberg AS, et al. (2015) Eicosapentaenoic and docosahexaenoic acid-enriched high fat diet delays the development of fatty liver in mice. Lipids Health Dis 14, 74.

40. Hold GL, Schwiertz A, Aminov RI, et al. (2003) Oligonucleotide probes that detect quantitatively significant groups of butyrateproducing bacteria in human faeces. Appl Environ Microbiol 69, 4320-4324.

41. Gibson GR, Beatty ER, Wang X, et al. (1995) Selective stimulation of bifidobacteria in the human colon by oligofructose and inulin. Gastroenterology 108, 975-982.

42. Niness KR (1999) Inulin and oligofructose: what are they? J Nutr 129, 1402S-1406S.

43. Xu L, Nagat N, Nagashimada M, et al. (2017) SGLT2 inhibition by empagliflozin promotes fat utilization and browning and 
attenuates inflammation and insulin resistance by polarizing $\mathrm{M} 2$ macrophages in diet-induced obese mice. Ebiomedicine $\mathbf{2 0}$, 137-149.

44. Sung PB (2012) Effect of oral administration of Jerusalem artichoke inulin on reducing blood lipid and glucose in STZ-induced diabetic rats. J Anim Vet Adv 10, 2501-2507.

45. Brown SD, Twells RC, Hey PJ, et al. (1998) Isolation and characterization of LRP6, a novel member of the low density lipoprotein receptor gene family. Biochem Biophys Res Commun 248, 879-888.

46. Rader K, Orlando RA, Lou X, et al. (2000) Characterization of ANKRA, a novel ankyrin in repeat protein that interacts with the cytoplasmic domain of megalin. J Am Soc Nephrol 11, 2167-2178.

47. Steinmetz A, Barbaras R, Ghalim N, et al. (1990) Human apolipoprotein A-IV binds to apolipoprotein A-I/A-II receptor sites and promotes cholesterol efflux from adipose cells. J Biol Chem 265, 7859-7863.

48. Dvorin E, Gorder NL, Benson DM, et al. (1986) Apolipoprotein A-IV: a determinant for binding and up take of high density lipoproteins by rat hepatocytes. J Biol Chem 261, 15714-15718.

49. Li-Hawkins J, Lund EG, Bronson AD, et al. (2000) Expression cloning of anoxysterol 7alpha-hydroxylase selective for 24-hydroxycholesterol. J Biol Chem 275, 16543-16549.

50. Deniz E (2012) Biochemistry, pp. 419-442. Croatia: Intech.
51. Caldas H \& Herman GE (2003) NSDHL, an enzyme involved in cholesterol biosynthesis, traffics through the Golgi and accumulates on ER membranes and on the surface of lipid droplets. Hum Mol Genet 12, 2981-2991.

52. Chiang JY (2004) Regulation of bile acid synthesis: pathways, nuclear receptors, and mechanisms. J Hepatol $\mathbf{4 0}$, 539-551.

53. Rousset X, Shamburek R, Vaisman B, et al. (2011) Lecithin cholesterol acyltransferase: an anti- or pro-atherogenic factor? Curr Atheroscler Rep 13, 249-256.

54. Zhang X, Shen D, Fang Z, et al. (2013) Human gut microbiota changes reveal the progression of glucose intolerance. PLOS ONE 8, e71108.

55. Wu XK, Ma CF, Han L, et al. (2010) Molecular characterisation of the faecal microbiota in patients with type II diabetes. Curr Microbiol 61, 69-78.

56. de Roos NM \& Katan MB (2000) Effects of probiotic bacteria on diarrhea, lipid metabolism, and carcinogenesis: a review of papers published between 1988 and 1998. Am J Clin Nutr 71, 405-411.

57. Patrick S (2015) Chapter 51 - bacteroides. In Molecular Medical Microbiology, vol. 2, pp. 917-944. Amsterdam: Elsevier.

58. Larsen N, Vogensen FK, Berg FW, et al. (2010) Gut microbiota in human adults with type 2 diabetes differs from non-diabetic adults. PLOS ONE 5, e9085. 